\title{
Effects of Different Amine Activators on the Monomer Conversion, Biaxial Flexural Strength, and Color Stability of Experimental Provisional Dental Restorations
}

\author{
Chawal Padunglappisit ${ }^{1}$ Siwanath Posaya-anuwat ${ }^{1}$ Varisara Sompoch ${ }^{1}$ \\ Poompat Piyawiwattanakoon ${ }^{1}$ Piyaphong Panpisut ${ }^{1,2, \odot}$ \\ ${ }^{1}$ Division of Restorative Dentistry, Faculty of Dentistry, Thammasat \\ University, Pathum Thani, Thailand \\ ${ }^{2}$ Thammasat University Research Unit in Dental and Bone Substitute \\ Biomaterials, Thammasat University, A. Klong Luang, Pathum \\ Thani, Thailand \\ Address for correspondence Piyaphong Panpisut, DDS, MSc, \\ PhD, Division of Restorative Dentistry, Faculty of Dentistry, \\ Thammasat University, 99 Moo 18, A. Klong1, Klong Luang, \\ Pathum Thani 12121, Thailand (e-mail: panpisut@staff.tu.ac.th).
}

Eur J Dent 2021;15:488-494

\begin{abstract}
Objective The aim was to assess the effect of different amine activators including N, $\mathrm{N}$-dimethyl-p-toluidine (DMPT) or Na-N-tolyglycine glycidyl methacrylate (NTGGMA) on chemical-activated monomer conversion, biaxial flexural strength (BFS), and color stability of composites for provisional dental restorations.

Materials and Methods Two formulations of composites containing either DMPT (D-temp) or NTGGMA (N-temp) were prepared. The degree of monomer conversion was assessed. The BFS of the materials was tested using the ball-on-ring testing jig. The color difference $\left(\Delta \mathrm{E}_{00}\right)$ of the materials after immersion in water was also determined. The commercial comparisons were Unifast (UF), Protemp (PT), Luxacrown, and Luxatemp (LT).

Results The monomer conversion of D-temp (57.4 $\pm 1.3 \%)$ was comparable to that of $\mathrm{N}$-temp $(59.0 \pm 1.3 \%)$. The conversion of both $\mathrm{D}$-temp and $\mathrm{N}$-temp were higher than that of PT $(48.1 \pm 3.4 \%)$ and LT $(48.0 \pm 1.6 \%)$. BFS of both D-temp $(164.2 \pm 18.1 \mathrm{MPa})$ and N-temp (168.6 $\pm 8.9 \mathrm{MPa}$ ) were comparable but higher than that of UF (119.8 \pm $13.6 \mathrm{MPa}) . \Delta \mathrm{E}_{00}$ of $\mathrm{D}$-temp $(2.7 \pm 0.7)$ and $\mathrm{N}$-temp $(2.5 \pm 0.8)$ were comparable but

Keywords

- composite resin

- temporary

- polymerization

- flexural strength

- color stability higher than that of other commercial materials (0.6-1.2).

Conclusion The use of DMPT or NTGGMA showed negligible effect on monomer conversion, BFS, and color stability of the experimental provisional restorations. The conversion and BFS of the experimental materials were in the range of that obtained from commercial bis-acryl-based materials. However, the color stability of the experimental materials was lower than that of commercial materials.
\end{abstract}

\section{Introduction}

Provisional dental restorations are commonly used during the temporization period between preparing teeth and the placement of final restoration to help maintaining prepared margins, spaces, periodontal health, masticatory functions, appearance, and vocal quality for the patient. ${ }^{1,2}$ The commonly used provisional materials include polymethyl methacrylate (PMMA) and bis-acryl resin composites which contain dimethacrylate monomers and fillers. ${ }^{3,4}$ These materials can be polymerized chemically which could facilitate the direct published online

February 3, 2021
DOI https://doi.org/

10.1055/s-0040-1721908

ISSN $1305-7456$
(C) 2021. European Journal of Dentistry.

This is an open access article published by Thieme under the terms of the Creative Commons Attribution-NonDerivative-NonCommercial-License, permitting copying and reproduction so long as the original work is given appropriate credit. Contents may not be used for commercial purposes, or adapted, remixed, transformed or built upon. (https://creativecommons.org/licenses/by-nc-nd/4.0/)

Thieme Medical and Scientific Publishers Pvt. Ltd., A-12, 2nd Floor, Sector 2, Noida-201301 UP, India 
fabrication technique. ${ }^{3}$ The technique involves the injection of material into the silicone index placed over the prepared tooth intraorally. The clinicians then allow the material to set either by light or chemical activations. The use of light activation significantly enhances physical properties of the material. ${ }^{5}$ However, the light curing option may not be possible if the transparent silicone is not available. Thus, the ability to cure chemically is still vitally important for the materials.

Tertiary amine enables the dissociation of chemical initiator, such as benzoyl peroxide (BP), to initiate polymerization of the materials. N, N-dimethyl-p-toluidine (DMPT; molecular weight of $135 \mathrm{~g} / \mathrm{mol}$ ) is the commonly used tertiary amine to enable polymerization of chemical-activated resin composites or cements. ${ }^{6.7}$ The major concern of DMPT is its toxicity. Various studies have reported that DMPT can be absorbed and distributed to various sites inducing toxic and carcinogenic effects. ${ }^{8-10}$ Hence, an alternative activator is needed.

Na-N-tolyglycine glycidyl methacrylate (NTGGMA) consists of methacrylate and amine groups in the structure (-Fig. 1). ${ }^{11}$ Hence, the monomer can be polymerized within the polymer network, thus reducing the risk of leaching of monomers. The monomer also contains carboxylic group which could potentially help to increase hydrophilic properties and promote the flow of material on the hydrophilic tooth surface. However, the hydrophilic group of NTGGMA may increase water sorption to the material that may subsequently reduce the strength and esthetic properties of the material..$^{2}$ The materials are required to exhibit sufficient mechanical strength and color stability to ensure patient satisfaction and function during temporization process.

The aim of this study was therefore to assess the effect of using different amine activator (NTGGMA vs. DMPT) on the degree of monomer conversion (MC), biaxial flexural strength (BFS), and color stability of the experimental provisional dental restorations. Commercial materials were used for comparison. The null hypothesis was that the use of different amine activators should not detrimentally affect the degree of MC, BFS, and color stability of the materials.

\section{Materials and Methods}

\section{Material Preparation}

The experimental composites for provisional restorations were prepared using the power-to-liquid mass ratio of 2.3:1. Powder phase of the experimental materials contained silanated borosilicate glass (Esstech Inc.; Essington, Pennsylvania,

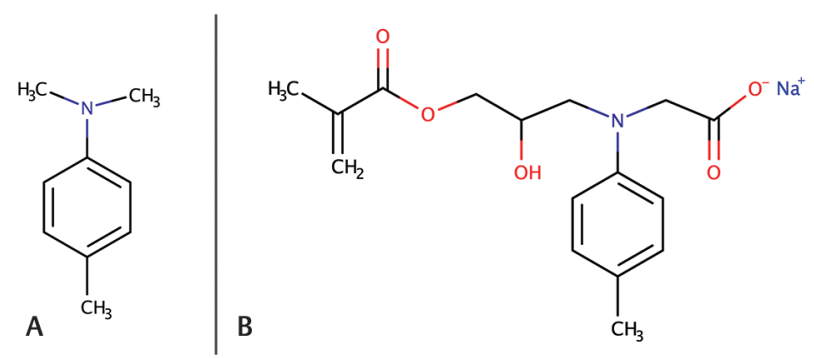

Fig. 1 Chemical structure of (A) DMPT (N, N-dimethyl-p-toluidine) and (B) NTGGMA (Na-N-tolyglycine glycidyl methacrylate).
United States). The liquid phase contained 70 wt\% urethane dimethacrylate (UDMA; lot no. MKCG8230, Sigma-Aldrich, St. Louis, Missouri, United States), 24 wt\% triethyleneglycol dimethacrylate (lot no. STBF9549V, Sigma-Aldrich), and 5 wt\% 2-hydroxyethyl methacrylate (HEMA; lot no. STBG6525, Sigma-Aldrich). For imitator liquid, $1 \mathrm{wt} \%$ BP (lot no. MKCF7091, Sigma-Aldrich) was added. For activator liquid, $1 \mathrm{wt} \%$ of DMPT (lot no. MKBX9809V, Sigma-Aldrich) or $2 \mathrm{wt} \%$ of NTGGMA (lot no. X8630050, Esstech Inc) was added. The experimental composites containing DMPT and NTGGMA were referred to as D-temp and N-temp, respectively.

The liquid phase was mixed using a magnetic stirrer for 1 hour. The mixed liquid was left for 24 hours before mixing with powder phase. The powder and liquid phases were weighed using a four-figure balance. The powder and liquid were hand-mixed using a plastic spatula ( 20 seconds until the paste was mixed homogenously). The mixed initiator and activator pastes were then loaded into the double-barrel syringe. The syringe was left in the upright position at room temperature for 24 hours to allow the release of air bubbles incorporated in the paste.

The experimental materials were mixed and injected using mixing tip with a dispenser Sulzer Mixpac AG, Switzerland. ${ }^{13}$ Commercially available provisional dental restorations including PMMA and bis-acryl-based composites were used as comparisons (-Table 1). The commercial materials were prepared according to the manufacturer's instruction.

\section{Monomer Conversion}

A Fourier-transform infrared spectroscopy (FTIR; Nicolet iS5, Thermo Fisher Scientific, Massachusetts, United States) equipped with an attenuated total reflection (ATR; ID7, Thermo Fisher Scientific) was used to determine the MC of the materials $(n=5)$. The mixed materials were placed in the metal circlip (1 $\mathrm{mm}$ in thickness and $10 \mathrm{~mm}$ in diameter) on the ATR diamond. The specimens were then covered with an acetate sheet. The FTIR spectra were recorded initially and after 10 minutes. The spectra at the region of 700 to $4,000 \mathrm{~cm}^{-1}$ with the resolution of $8 \mathrm{~cm}^{-1}$ were obtained. ${ }^{14}$ The test was performed at $25 \pm 1^{\circ} \mathrm{C}$. The degree of MC was calculated using the following equation:

$$
M C(\%)=\frac{100\left(B_{0}-B_{t}\right)}{B_{0}}
$$

where $B_{0}$ and $B_{t}$ are the absorbance of the $\mathrm{C}-\mathrm{O}$ peak $\left(1,320 \mathrm{~cm}^{-1}\right)$ above background level at $1,335 \mathrm{~cm}^{-1}$ initially and after time $t^{15}$

\section{Biaxial Flexural Strength and Biaxial Flexural Modulus}

The materials were loaded into the metal circlip (1 $\mathrm{mm}$ in thickness and $10 \mathrm{~mm}$ in diameter $(n=8)$. The specimens were covered with an acetate sheet and left at room temperature for 24 hours to allow the completion of polymerization. The disc specimens were then removed, trimmed excess, and placed in a tube containing $10 \mathrm{~mL}$ of deionized water. They were incubated at $37^{\circ} \mathrm{C}$ for 24 hours and 4 weeks. Then, the discs were 
Table 1 The composition of commercial materials

\begin{tabular}{|c|c|c|c|}
\hline Materials & Composition & Lot no. & Suppliers \\
\hline \multirow[t]{2}{*}{$\begin{array}{l}\text { Unifast Trad } \\
\text { (UF) }\end{array}$} & $\begin{array}{l}\text { Powder: ethyl-methyl methacrylate monomer, polymethyl methacrylate, } \\
\text { barbituric acid derivative, organic copper compound, pigments }\end{array}$ & \multirow[t]{2}{*}{1808271} & \multirow[t]{2}{*}{$\begin{array}{l}\text { GC Corporation; Tokyo, } \\
\text { Japan }\end{array}$} \\
\hline & $\begin{array}{l}\text { Liquid: methyl methacrylate, N,N-dimethyl-p-toluidine trimethylolpropane, } \\
\text { ethylene glycol dimethacrylate }\end{array}$ & & \\
\hline Luxacrown (LC) & Inorganic and organic filler, matrix of multifunctional acrylates & 770658 & $\begin{array}{l}\text { DMG; Hamburg, } \\
\text { Germany }\end{array}$ \\
\hline $\begin{array}{l}\text { Luxatemp } \\
\text { (LT) }\end{array}$ & $\begin{array}{l}\text { Polymethyl methacrylate, } \mathrm{SiO}_{2} \text {, bisphenol A-glycidyl methacrylate, urethane } \\
\text { dimethacrylate, other dimethacrylates }\end{array}$ & 802411 & $\begin{array}{l}\text { DMG; Hamburg, } \\
\text { Germany }\end{array}$ \\
\hline \multirow[t]{2}{*}{$\begin{array}{l}\text { Protemp } 4 \\
\text { (PT) }\end{array}$} & $\begin{array}{l}\text { Base: Ethoxylate bisphenol-A dimethacrylate, silane-treated } \\
\text { amorphous silica, reaction product of 1,6-diisocyanatohexane with } \\
\text { 2-[(2-methacryloyl) ethyl]6-hydroxyhexonate and 2-hydroxyethyl } \\
\text { methacrylate }\end{array}$ & \multirow[t]{2}{*}{4249947} & \multirow[t]{2}{*}{$\begin{array}{l}\text { 3M ESPE; St. Paul, MN, } \\
\text { USA }\end{array}$} \\
\hline & $\begin{array}{l}\text { Catalyst: ethanol, 2,2'-[(1-methylethylidene)bis(4,1-phenyleneoxy]bis-diace- } \\
\text { tate, benzyl-phenyl-barbituric acid, silane-treated silica }\end{array}$ & & \\
\hline
\end{tabular}

Note: The materials are either polymethyl methacrylate-based material (Unifast Trad) or bis-acryl-based materials (Luxacrown, Luxatemp, and Protemp 4). The ingredients of Luxacrown and Luxatemp in each catalyst or base pastes were not supplied by suppliers.

removed, blotted dry, and mounted in the ball-on-ring testing jig. BFS test was performed under the mechanical testing frame (AGSX, Shimadzu, Kyoto, Japan) using $500 \mathrm{~N}$ load cell with the crosshead speed of $1 \mathrm{~mm} / \mathrm{min}$. The BFS (Pa) of the specimen was obtained using the following equation ${ }^{16}$ :

$$
B F S=\frac{F}{d^{2}}\left\{(1+i)\left[0.485 \ln \left(\frac{r}{d}\right)+0.52\right]+0.48\right\}
$$

where $F$ is the load at failure $(\mathrm{N}), d$ is the specimen's thickness (m), $r$ is the radius of circular support ( $m$ ), and $\hat{\imath}$ is Poison's ratio (0.3). Additionally, biaxial flexural modulus (BFM) was calculated using the following equation ${ }^{17}$ :

$$
B F M=\left(\frac{\Delta H}{\Delta W_{c}}\right) \times\left(\frac{\hat{a}_{c} d^{2}}{q^{3}}\right)
$$

where $\Delta H / \Delta W c$ is the rate of change of load with regards to central deflection or gradient of force versus displacement curve $(\mathrm{N} / \mathrm{m})$, âc is the center deflection junction $(0.5024),{ }^{18}$ and $q$ is the ratio of support radius to the radius of disc. Additionally, the fracture surface of tested specimens at 4 weeks was investigated using a scanning electron microscope (SEM; JSM 7800F, JEOL Ltd., Tokyo, Japan).

\section{Color Stability}

The disc specimens ( $n=3$ ) were prepared and immersed in $10 \mathrm{~mL}$ of deionized water. The specimens were incubated at $37^{\circ} \mathrm{C}$ for 3 weeks. The CIELab coordinates of all specimens before and after immersion were measured using a dental spectrophotometer (Easyshade V; VITA Zahnfabrik, Baden-Württemberg, Germany). The spectrophotometer was calibrated according to the manufacturer's instructions prior to the measurement. The specimens were placed over the opaque white background. The illumination of the room was 850 lux which was measured by a light meter (LX1330B Light Meter; Dr. Meter Digital Illuminance, StellarNet Inc.; Florida, United States). ${ }^{19}$ The spectrophotometer probe tip was positioned perpendicular to the center of the specimens until the completion of measurement. The color coordinates
(CIE $L^{*}, a^{*}, b^{*}, C^{*}$, and $h^{0}$ ) were then recorded. The $L^{*}, a^{*}$, and $b^{*}$ parameters refer to value axis, red-green axis, and yellow-blue axis, respectively. In addition, $C^{*}$ and $h^{\circ}$ were chroma and hue angle.

The measurement for each specimen was performed in triplicate. Color differences or color changes of the composites after immersion in deionized water was calculated using the CIEDE2000 $\left(E_{00}\right)$ formula ${ }^{20}$ :

$$
E_{00}=\left[\left(\frac{\Delta L^{\prime}}{K_{L} S_{L}}\right)^{2}+\left(\frac{\Delta C^{\prime}}{K_{C} S_{C}}\right)^{2}+\left(\frac{\Delta H^{\prime}}{K_{H} S_{H}}\right)^{2}+R_{T}\left(\frac{\Delta C^{\prime}}{K_{C} S_{C}}\right)\left(\frac{\Delta H^{\prime}}{K_{H} S_{H}}\right)\right]^{1 / 2}
$$

where $\Delta L^{\prime}, \Delta C^{\prime}$, and $\Delta H^{\prime}$ represent the changes in lightness, chroma, and hue, respectively. Furthermore, $R_{T}$ is a rotation function related to the interaction between chroma and hue differences in the blue region. Additionally, $S_{L}, S_{C}$ and $S_{H}$ are weighting functions and $K_{L}, K_{C}$, and $K_{H}$ are correction terms for experimental conditions.

\section{Statistical Analysis}

Values reported in the current study are mean \pm standard deviation. The data were analyzed using Prism 9 (GraphPad Software; San Diego, California, United States). Normality of the data was tested using the Shapiro-Wilk test. For normally distributed data (MC, BFS, color stability), one-way analysis of variance followed by post hoc Tukey multiple comparison was employed. For non-normally distributed data (BFM), Kruskal-Wallis test followed by Dunn's multiple comparisons was used. Significance level was set at $p=0.05$. Additionally, power analysis was performed using $G^{*}$ Power version 3.1.9.6 (University in Düsseldorf, Germany) which indicated that the sample used in each test gave power $>0.95$ at $\alpha=0.05$.

\section{Results}

\section{Degree of Monomer Conversion}

The highest MC was obtained from Unifast (UF) (75.6 $\pm 1.5 \%)$ ( -Fig. 2). D-temp (57.4 $\pm 1.3 \%)$ exhibited comparable MC to 
N-temp $(59.0 \pm 1.3 \%)(p=0.8346)$. The conversion of both D-temp and N-temp were similar to that of Luxacrown (LC) $(60.1 \pm 2.9 \%)(p=0.3676,0.9626)$. D-temp and N-temp however showed significantly higher MC than Luxatemp (LT) (48.0 $\pm 1.6 \%)(p<0.01)$ and Protemp (PT) $(48.1 \pm 3.4 \%)(p<0.01)$.

\section{Biaxial Flexural Strength and Biaxial Flexural Modulus}

At 24 hours, the highest and lowest BFS were obtained from LT (214.1 $\pm 29.7 \mathrm{MPa})$ and UF $(119.8 \pm 13.6 \mathrm{MPa})$, respectively ( - Fig. 3A). The BFS of D-temp $(164.2 \pm 18.1 \mathrm{MPa})$ was comparable to that of N-temp $(168.6 \pm 8.9 \mathrm{MPa})(p=4332)$. The BFS of both D-temp and N-temp were significantly higher than that of UF $(p=0.008,0.002)$ but comparable to that of PT $(185.6 \pm 19.0 \mathrm{MPa})(p=0.2783,0.5315)$ and LC $(193.5 \pm 17.2$ MPa) $(p=0.0540,0.1452)$. The BFS of D-temp and N-temp was reduced to $121.1 \pm 31.2$ and $143.2 \pm 12.8 \mathrm{MPa}$ after immersion in simulated body fluid for 4 weeks. The BFS of D-temp and N-temp at 4 weeks was significantly lower than that of PT $(187.5 \pm 26.5 \mathrm{MPa}), \mathrm{LC}(173.6 .5 \pm 23.8 \mathrm{MPa})$, and LT $(184.7 \pm 24.0 \mathrm{MPa})(p<0.05)$.

The highest and lowest BFM at 24 hours were obtained from N-temp ( $4.0 \pm 0.2 \mathrm{GPa})$ and UF (1.3 $\pm 0.2 \mathrm{GPa})$, respectively ( - Fig. 3B). BFM of N-temp was comparable to that

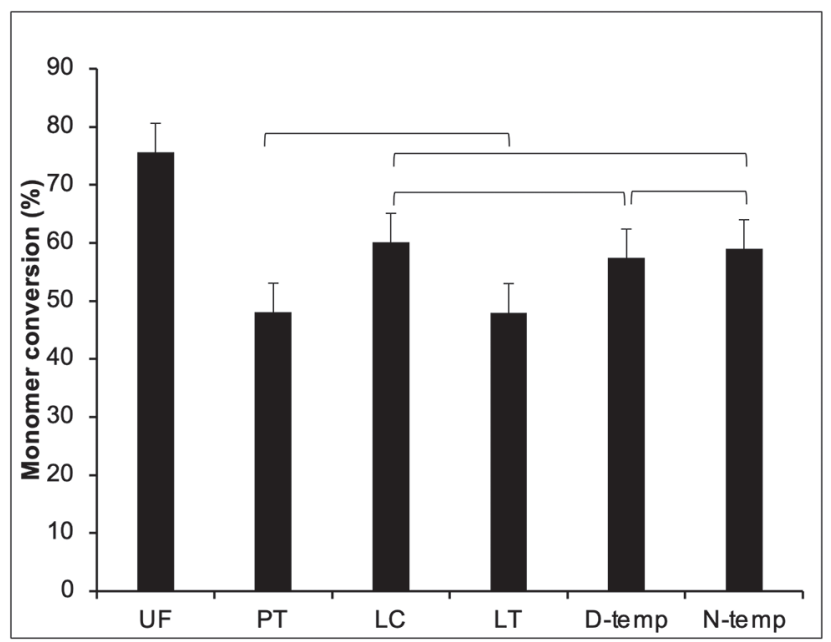

Fig. 2 Monomer conversion of Unifast (UF), Protemp (PT), Luxacrown (LC), Luxatemp (LT), and experimental composites (D-temp and $\mathrm{N}$-temp). Error bars are standard deviation (SD) $(n=5)$. Lines represent $p>0.05$. of D-temp $(3.0 \pm 0.4 \mathrm{GPa})(p=0.6267)$ but was significantly higher than that of UF $(p<0.01)$, PT $(2.0 \pm 0.2 \mathrm{GPa})$ $(p=0.0001)$, and LC $(2.6 \pm 0.4 \mathrm{GPa})(p=0.0382)$. After 4 weeks, the values of $\mathrm{D}$-temp and $\mathrm{N}$-temp were reduced to $2.5 \pm 0.7$ and $3.5 \pm 0.4 \mathrm{GPa}$, respectively. The highest and lowest observed mean values were obtained from N-temp ( $3.5 \pm 0.4 \mathrm{GPa})$ and $\mathrm{UF}(1.5 \pm 0.5 \mathrm{GPa})$, respectively.

Fracture surfaces of the tested specimens at 4 weeks were examined under SEM ( $\bullet$ Fig. 4). PT, LC, and LT showed smooth fractured surfaces. However, multiple voids with diameter of 20 to $50 \mu \mathrm{m}$ in the bulk of materials were detected on the fracture surface of D-temp and N-temp.

\section{Color Stability}

The highest and lowest observed color difference $\left(\Delta \mathrm{E}_{00}\right)$ were obtained from D-temp $(2.69 \pm 0.66)$ and UF $(0.55 \pm 0.17)$, respectively ( - Fig. 5$). \Delta \mathrm{E}_{00}$ of D-temp and N-temp (2.46 \pm 0.78$)$ were comparable $(p=0.997)$ but were significantly higher than that of UF $(p=0.0124$, $0.0266)$. The color difference of UF was similar to that of PT $(0.91 \pm 0.25)(p=0.9800), \mathrm{LC}(1.16 \pm 0.84)(p=0.8399)$, and LT $(0.98 \pm 0.72)(p=0.9544)$. Additionally, PT exhibited significantly lower color difference than D-temp ( $p=0.0396)$.

\section{Discussion}

Currently, one of the main chemical activators used in resin-based materials for provisional dental restorations is DMPT. However, the major concern of this monomer is its toxic effects. The aim of this preliminary study was therefore to investigate the effect of using different amine activators (DMPT or NTGGMA) on degree of MC, BFS, and color stability of the materials. The hypothesis was accepted as the use of DMPT or NTGGMA showed no detrimental effect to MC, BFS, and color stability of the materials. It should be noted that the current study is an in vitro study. Hence, the clinically relevant aspects should be carefully interpreted.

\section{Degree of Monomer Conversion}

High degree of MC of provisional restorations may help to ensure adequate physical and mechanical properties for the restorations. ${ }^{21}$ Additionally, it was expected that the high conversion could also reduce the risk of unreacted monomer
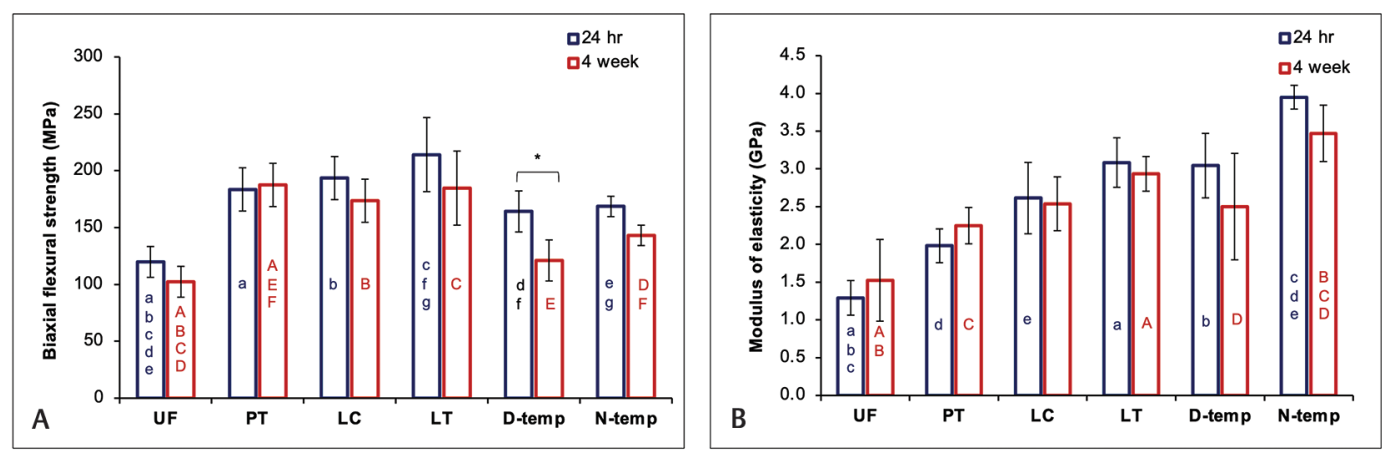

Fig. 3 (A) Biaxial flexural strength (BFS) and (B) biaxial flexural modulus (BFM) of Unifast after immersion in water for 24 hours and 4 weeks. Error bars are standard deviation (SD) $(n=8)$. Same lower-case and upper-case letters denoted $p<0.05$ for the strength at 24 hours and 4 weeks, respectively. Stars $\left({ }^{*}\right)$ represent $p<0.05$ for the strength of the same material. 

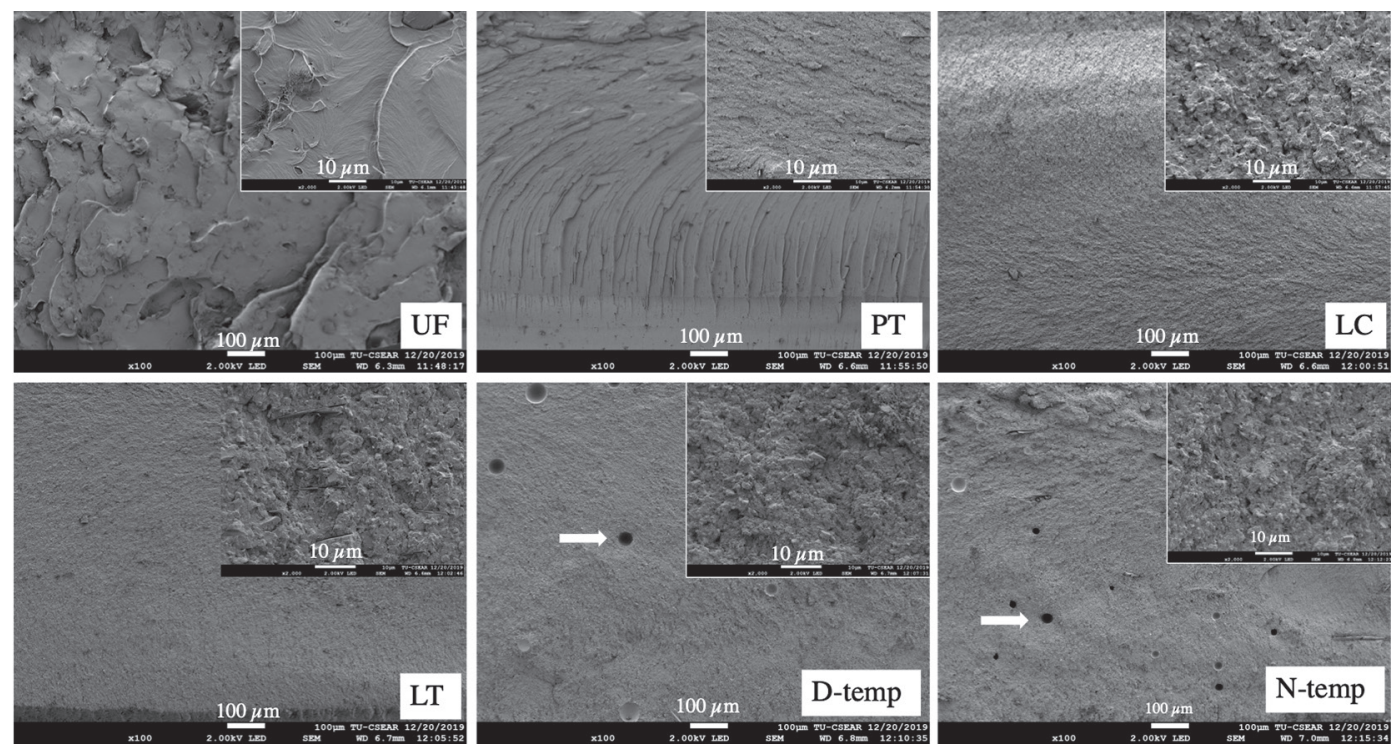

Fig. 4 Scanning electron microscope (SEM) images of fracture surface from Unifast (UF), Protemp (PT), Luxacrown (LC), Luxatemp (LT), and experimental composites ( $\mathrm{D}$-temp and $\mathrm{N}$-temp). The scale bars represent 100 and $10 \mu \mathrm{m}$ in length. Voids in the core of materials were observed with D-temp and N-temp (arrows).

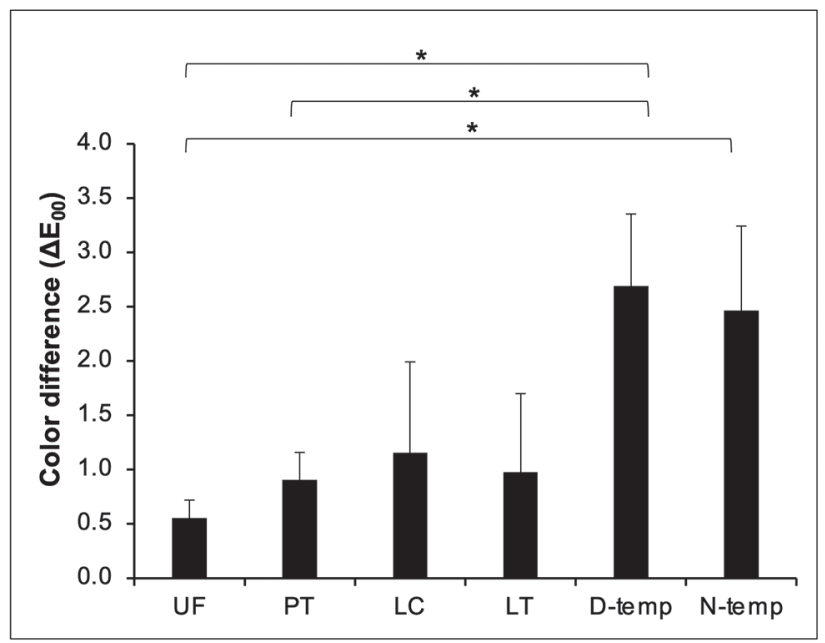

Fig. 5 Color difference $\left(\mathrm{E}_{00}\right)$ of Unifast (UF), Protemp (PT), Luxacrown (LC), Luxatemp (LT), and experimental composites (D-temp and $\mathrm{N}$-temp) after immersion in deionized water for 3 weeks. Error bars are standard deviation $(\mathrm{SD})(n=3)$. Stars $\left({ }^{*}\right)$ represent $p<0.05$.

release that may cause cytotoxic effects. ${ }^{22}$ It is known that monomer with low glass transition temperature $(\mathrm{Tg})$ and high flexibility could contribute to high degree of MC of the polymer. ${ }^{17,23}$ The highest MC was detected with PMMA-based material (UF) which could be due to the use of low molecular weight methyl methacrylate monomer (molecular weight = $101 \mathrm{~g} / \mathrm{mol}$ ). However, high MC usually associates with high exothermic reaction which may affect dentin-pulp complex. ${ }^{24}$ A study demonstrated that PMMA exhibited increase in temperature during setting by 4.2 to $11.6^{\circ} \mathrm{C}$ which was higher than that of bis-acryl composite $\left(2.0-6.6^{\circ} \mathrm{C}\right) .^{4}$

It should be mentioned that the concentration of DMPT (1 wt \%) was lower than NTGGMA (2 wt\%). The pilot study showed that using 2 wt\% DMPT and 1 wt\% NTGGMA enabled suitable handling characteristics. The MC of D-temp and N-temp were higher than that of two commercial bis-acryl-based materials (PT and LT). The primary base monomer of D-temp and N-temp was UDMA. The Tg of UDMA $\left(-38^{\circ} \mathrm{C}\right)^{25}$ was lower than bis-GMA $\left(\mathrm{Tg}=-10^{\circ} \mathrm{C}\right)$ which was the primary base monomer of bis-acryl-based materials (PT, LT). However, the actual composition of the monomers of commercial materials was not supplied from the manufacturers.

\section{Biaxial Flexural Strength and Biaxial Flexural Modulus}

The provisional restorations required adequate strength to ensure the survival upon the repeated chewing forces before the placement of definitive restoration. ${ }^{3}$ The required flexural strength from 3-point bending test for polymer-based crown material according to the BS ISO 10477-2018 was $50 \mathrm{MPa} .{ }^{26}$ The current study employed BFS instead of 3-point bending test as stated in the standard. It is suggested that BFS test could give similar results to 3-point bending test but with more reproducibility. ${ }^{27}$ The results from the current study suggested that flexural strength of the experimental composites should pass the standard even after aging in water for 4 weeks.

The strength of dimethacrylate-based composites (PT, LT, LC, D-temp, and N-temp) was higher than of the strength obtained from monomethacrylate-based materials (UF). This was in accordance with the previous studies.2,28 The lowest BFS and modulus was obtained from UF which could be due to the lack of reinforcing fillers in the material. Additionally, the linear structure of monomethacrylate polymer and the lack of cross-links between polymer chains of UF may result in the low rigidity and strength. ${ }^{2}$ The 24 -hour flexural strength of commercial materials in the current study was higher than that reported in the published studies (UF $\sim 64-111 \mathrm{MPa},{ }^{28-30} \mathrm{PT} \sim 85-113 \mathrm{MPa},{ }^{29,31} \mathrm{LT} \sim 81.7 \mathrm{MPa}^{5}$ ). The possible explanation could be due to the use of different protocol for specimen preparation. In the current study, 
the specimens were left undisturbed in the metal circlip at room temperature for 24 hours prior to immersion. The delay of specimen removal may therefore allow polymerization reaction to continue, thus increasing the cross-links polymer network and strength of the materials. ${ }^{32}$ The highest modulus of elasticity was obtained from N-temp. This may be due to the increase in filler load of the experimental materials (69.7 wt\%) which was higher than that of commercial materials (30.8-39.3 wt\%). ${ }^{5}$ The high level of fillers may then increase the stiffness of the materials. ${ }^{33}$ The high stiffness and rigidity of the experimental materials may be considered suitable for temporizing the long-span fixed dental prostheses.

The fracture surface of PT demonstrated smoother and more homogenous surface compared with other bis-acryl-based materials. ${ }^{34}$ This may be due to the lower filler load $(\sim 30.8 \mathrm{wt} \%)^{5}$ or smaller filler diameter of PT compared with other materials. The bis-acryl-based materials and the experimental materials were mixed using the mixing tips which may decrease the risk of air bubbles incorporation. ${ }^{35}$ Multiple voids were detected in the fracture surfaces of D-temp and N-temp ( - Fig. 4 ). This could be due to the incorporation of air bubbles during the hand mixing of powder and liquid to produce initiator/activator pastes. In the future work, the mixed paste should be stored in a vacuum to help release air bubbles in the materials.

The increase in immersion time enabled materials to absorb water which led to polymer plasticization, which could reduce the physical/mechanical properties of the materials. ${ }^{36}$ The use of NTGGMA which contained hydrophilic group (carboxyl group) showed no significance on the strength. It was expected that the high MC and the incorporation of salinized glass fillers may help maintain mechanical strength. ${ }^{2}$ The experimental provisional materials however showed large decrease in strength after immersion for 4 weeks compared with commercial materials. The possible explanation could be that the experimental materials contained HEMA. The addition of HEMA was expected to promote wetting of the materials on the hydrophilic tooth surface. The hydrophilicity of HEMA may encourage water sorption and reduce strength of the materials. ${ }^{37}$ However, the strength of the experimental provisional materials after 4-week immersion were still higher than that required by the ISO standard.

\section{Color Stability}

The degree of color changes of provisional materials was associated with various factors such as chemical properties of the materials, filler size, water sorption, the incorporation of air bubbles, and degree of cross-liking molecules. ${ }^{38}$ It was proposed that perceptibility threshold which represent minimum color difference identifiable by viewer was when $\Delta \mathrm{E}_{00}=0.8 .^{39}$ Additionally, the acceptability threshold (AT) which indicate the level of color difference that was acceptable by viewer is when $\Delta \mathrm{E}_{00}=1.8$. Hence, it is expected that the materials should exhibited color difference within those range. The $\Delta \mathrm{E}_{00}$ of all experimental materials (0.6-1.2) were within the range of both perceptibility threshold and AT. The high MC of experimental composites was expected to reduce color change of the materials. However, the color differences of both D-temp (2.7) and N-temp (2.5) were higher than AT level. This could be due to the use of hydrophilic HEMA polymer which may promote water sorption and affect color stability of the material. ${ }^{38,40}$

\section{Conclusion}

Within the limitation of this study, the following conclusions can be drawn:

- The use of NTGGMA or DMPT in the current study showed no detrimental effect on MC, BFS, and color stability of the experimental provisional dental restorations.

- The MC and BFS of experimental materials were in the range of those observed with the commercial composite for provisional restorations. The strength was also higher than that required by the ISO standard.

- The color stability of experimental materials was lower than that of the commercial provisional materials.

\section{Funding}

This project was supported by Thammasat University Research Fund (Contract No. TUGR 2/53/2562).

\section{Conflict of Interest}

None declared.

\section{Acknowledgment}

The authors are grateful for the support from Thammasat University Research Unit in Dental and Bone Substitute Biomaterials, Thammasat University, the Faculty of Dentistry Thammasat University, and Thammasat University Center of Scientific Equipment for Advanced Research (TUCSEAR). Sulzer Mixpac AG (Switzerland) has provided syringes and mixing dispenser

\section{References}

1 Patras M, Naka O, Doukoudakis S, Pissiotis A. Management of provisional restorations' deficiencies: a literature review. J Esthet Restor Dent 2012;24(1):26-38

2 Astudillo-Rubio D, Delgado-Gaete A, Bellot-Arcís C, MontielCompany JM, Pascual-Moscardó A, Almerich-Silla JM. Mechanical properties of provisional dental materials: a systematic review and meta-analysis. PLoS One 2018; 13(2):e0193162

3 Keys WF, Keirby N, Ricketts DNJ. Provisional Restorations - A Permanent Problem?. Dent Update 2016;43(10):908-914 doi:10.12968/denu.2016.43.10.908

4 Ha JY, Kim SH, Kim KH, Kwon TY. Influence of the volumes of bis-acryl and poly(methyl methacrylate) resins on their exothermic behavior during polymerization. Dent Mater J 2011;30(3):336-342

5 Akiba S, Takamizawa T, Tsujimoto A, et al. Influence of different curing modes on flexural properties, fracture toughness, and wear behavior of dual-cure provisional resin-based composites. Dent Mater J 2019;38(5):728-737

6 Koyama J, Fukazawa K, Ishihara K, Mori Y. In situ surface modification on dental composite resin using 2-methacryloyloxyethyl phosphorylcholine polymer for controlling plaque 
formation. Mater Sci Eng C Mater Biol Appl 2019;104:109916 doi:10.1016/j.msec.2019.109916

7 Zhou X, Huang X, Li M, et al. Development and status of resin composite as dental restorative materials. J Appl Polym 2019;136:48180

8 Dunnick JK, Brix A, Sanders JM, Travlos GSN. N,N-dimethylp-toluidine, a component in dental materials, causes hematologic toxic and carcinogenic responses in rodent model systems. Toxicol Pathol 2014;42(3):603-615

9 Dunnick JK, Shockley KR, Morgan DL, et al. Hepatic transcriptomic alterations for N,N-dimethyl-p-toluidine (DMPT) and p-toluidine after 5-day exposure in rats. Arch Toxicol 2017; 91(4):1685-1696

10 Pratap B, Gupta RK, Bhardwaj B, Nag M. Resin based restorative dental materials: characteristics and future perspectives. Jpn Dent Sci Rev 2019;55(1):126-138

11 Van Landuyt KL, Snauwaert J, De Munck J, et al. Systematic review of the chemical composition of contemporary dental adhesives. Biomaterials 2007;28(26):3757-3785

12 Tay JS, Choong BB, Ooi IH, Tan BS. Effect of trifluoroethyl methacrylate comonomer on physical properties of Bis-GMA based dental composites. Dent Mater J 2019;38(2):226-232

13 Panpisut P, Khan MA, Main K, et al. Polymerization kinetics stability, volumetric changes, apatite precipitation, strontium release and fatigue of novel bone composites for vertebroplasty. PLoS One 2019;14(3):e0207965

14 Panpisut P, Toneluck A. Monomer conversion, dimensional stability, biaxial flexural strength, and fluoride release of resin-based restorative material containing alkaline fillers. Dent Mater J 2020;39(4):608-615

15 Panpisut P, Liaqat S, Zacharaki E, Xia W, Petridis H, Young AM. Dental composites with calcium / strontium phosphates and polylysine. PLoS One 2016;11(10):e0164653

16 Panpisut P, Monmaturapoj N, Srion A, Toneluck A, Phantumvanit P. Physical properties of glass ionomer cement containing pre-reacted spherical glass fillers. Braz Dent J 2020;31(4): 445-452

17 Walters NJ, Xia W, Salih V, Ashley PF, Young AM. Poly(propylene glycol) and urethane dimethacrylates improve conversion of dental composites and reveal complexity of cytocompatibility testing. Dent Mater 2016;32(2):264-277

18 Higgs WA, Lucksanasombool P, Higgs RJ, Swain MV. A simple method of determining the modulus of orthopedic bone cement. J Biomed Mater Res 2001;58(2):188-195

19 Revilla-León M, Umorin M, Özcan M, Piedra-Cascón W. Color dimensions of additive manufactured interim restorative dental material. J Prosthet Dent 2020;123(5):754-760

20 Ardu S, Duc O, Di Bella E, Krejci I. Color stability of recent composite resins. Odontology 2017;105(1):29-35

21 Ozkomur A, Fortes CB. Effects of postpolymerization microwave irradiation on provisional dental acrylics: physical and mechanical properties. J Appl Biomater Funct Mater 2016; 14(3):e302-e306

22 Schulz SD, Laquai T, Kümmerer $\mathrm{K}$, Bolek $\mathrm{R}$, MerschSundermann V, Polydorou O. Elution of monomers from provisional composite materials. Int J Polym Sci 2015; 2015:1-7

23 SideridouI,TserkiV,PapanastasiouG.Effectofchemicalstructure on degree of conversion in light-cured dimethacrylate-based dental resins. Biomaterials 2002;23(8):1819-1829
24 Farah RI. Effect of simulated pulpal blood flow rate on the rise in pulp chamber temperature during direct fabrication of exothermic provisional restorations. Int Endod J 2017;50(11):1097-1103

25 Stansbury JW. Dimethacrylate network formation and polymer property evolution as determined by the selection of monomers and curing conditions. Dent Mater 2012;28(1):13-22

26 British Standard, Dentistry. Polymer-Based Crown and Veneering Materials (ISO 10477:2018). Switzerland: BSI Standards; 2018

27 Ilie N, Hilton TJ, Heintze SD, et al. Academy of dental materials guidance-resin composites: part I-mechanical properties. Dent Mater 2017;33(8):880-894

28 Shibasaki S, Takamizawa T, Suzuki T, et al. Influence of different curing modes on polymerization behavior and mechanical properties of dual-cured provisional resins. Oper Dent 2017;42(5):526-536

29 Mehrpour H, Farjood E, Giti R. Barfi Ghasrdashti A, Heidari $\mathrm{H}$. Evaluation of the flexural strength of interim restorative materials in fixed prosthodontics. J Dent (Shiraz) 2016;17(3):201-206

30 Shirako T, Churei H, Iwasaki N, Takahashi H, Ueno T. Evaluation of the flexural properties of a new temporary splint material for use in dental trauma splints. J Dent Sci 2017;12(3):308-310

31 Alp G, Murat S, Yilmaz B. Comparison of flexural strength of different CAD/CAM PMMA-based polymers. J Prosthodont 2019;28(2):e491-e495

32 Kim K, Sinha J, Gao G, et al. High-efficiency radical photopolymerization enhanced by autonomous dark cure. Macromolecules 2020;53:5034-5046

33 Fu SY, Feng XQ Lauke B, Mai YW. Effects of particle size, particle/matrix interface adhesion and particle loading on mechanical properties of particulate-polymer composites. Compos B Eng 2008;39:933-961

34 Mei ML, So SYC, Li H, Chu CH. Effect of heat treatment on the physical properties of provisional crowns during polymerization: an in vitro study. Materials (Basel) 2015;8(4): 1766-1777

35 Silva NRD, Rodrigues MP, Bicalho AA, Soares PBF, Price RB, Soares CJ. Effect of resin cement mixing and insertion method into the root canal on cement porosity and fiberglass post bond strength. J Adhes Dent 2019;21(1):37-46

36 Ferracane JL. Hygroscopic and hydrolytic effects in dental polymer networks. Dent Mater 2006;22(3):211-222

37 Mehdawi IM, Pratten J, Spratt DA, Knowles JC, Young AM. High strength re-mineralizing, antibacterial dental composites with reactive calcium phosphates. Dent Mater 2013;29(4):473-484

38 Bastos NA, Bitencourt SB, de Mello IP, de Abreu CW, Bombonatti JFS, Silva MM. Effect of different beverages and storage period on bis-acryl color stability using two assessment methods. J Esthet Restor Dent 2020;32(6):575-580

39 Paravina RD, Ghinea R, Herrera LJ, et al. Color difference thresholds in dentistry. J Esthet Restor Dent 2015;27(Suppl 1) :S1-S9

40 Fonseca AS, Labruna Moreira AD, de Albuquerque PP, de Menezes LR, Pfeifer CS, Schneider LF. Effect of monomer type on the CC degree of conversion, water sorption and solubility, and color stability of model dental composites. Dent Mater 2017;33(4):394-401 